\title{
Neoadjuvant therapy for resectable and borderline resectable pancreatic cancer
}

\author{
Rachit Kumar • Salma K. Jabbour
}

Received: 27 August 2013 / Accepted: 28 August 2013 / Published online: 1 October 2013

(C) Springer-Verlag Berlin Heidelberg 2013

\begin{abstract}
Neoadjuvant chemoradiation for resectable and borderline resectable pancreatic cancer has been widely investigated in the past two decades. Research demonstrates that this therapy may help improve surgical margins, reduce rates of lymph node positivity, allow for earlier initiation of systemic therapy, and select for patients with aggressive disease in whom surgery may not be warranted. This review presents the data for neoadjuvant chemoradiation in pancreatic cancer with a focus on resectable and borderline resectable disease.
\end{abstract}

Keywords Pancreatic cancer · Neoadjuvant therapy · Radiation therapy $\cdot$ Resectable $\cdot$ Borderline resectable

\section{Introduction}

Despite the dismal 5-year overall survival of $<5 \%$ for pancreatic cancer, resection offers the only hope for cure. Patients with resectable pancreatic tumors who undergo resection have a far superior survival compared to patients who do not undergo resection [1]. Unfortunately, only $15-20 \%$ of patients will present with resectable or borderline resectable disease [2]. While the median survival of early-stage pancreatic cancer patients is approximately 20-24 months, the median survival for those with locally advanced (unresectable) disease is 9 15 months [2]. Given the importance of identifying patients in

\section{R. Kumar}

Department of Radiation Oncology and Molecular Radiation

Sciences, Sidney Kimmel Comprehensive Cancer Center,

The Johns Hopkins University, Baltimore, MD, USA

\section{S. K. Jabbour $(\bowtie)$}

Department of Radiation Oncology, Rutgers Cancer Institute of New Jersey, Robert Wood Johnson Medical School, Rutgers University, 195 Little Albany Street, New Brunswick, NJ 08903, USA e-mail: jabbousk@cinj.rutgers.edu whom surgical resection is possible, careful assessment of tumor involvement of the celiac, superior mesenteric, and hepatic arteries, along with accompanying veins, is paramount preoperatively (utilizing a pancreatic protocol CT) and intraoperatively. To be considered fully resectable, pancreatic masses should have no visible metastatic sites, clear fat planes around the key central arteries (celiac, superior mesenteric, and hepatic), and no evidence of abutment, distortion, or encasement of the portal vein or superior mesenteric vein [3].

While a TNM (tumor-node-metastasis) staging system has been developed for pancreatic cancer, a consensus guideline utilizing surgical resectability (Table 1 ) has been developed by a joint committee of the American Hepato-Pancreato-Biliary Association (AHPBA), Society of Surgical Oncology (SSO), and the Society for the Surgery of the Alimentary Tract (SSAT) $[3,4]$. These consensus guidelines specify that a patient with tumor abutment, but with $\leq 180^{\circ}$ involvement of the superior mesenteric, celiac, or hepatic arteries, is considered to be borderline resectable (Fig. 1) [3]. Katz and colleagues from the MD Anderson Hospital (MDAH) also include in this category patients in whom there is a clinical concern for nodal involvement or suspicion for metastatic disease by imaging, as well as patients with marginal performance status [5]. This is an important distinction as many of these patients would previously have been considered locally advanced and not appropriate for surgical resection. However, this subgroup of patients has been the subject of many retrospective and prospective analyses regarding the use of neoadjuvant therapy in the hope of sterilizing the operative bed and downstaging the pancreatic tumor to permit a curative resection.

The advantages of neoadjuvant chemotherapy or radiotherapy for pancreatic cancer include the ability to select patients who may either be chemo- or radio-responsive and may be downstaged by upfront therapy, or not operating on those who progress or clinically deteriorate during induction therapy. Also, surgeons may be better able to achieve an R0 
Table 1 The AHPBA/SSO/SSAT pre-treatment staging system of pancreatic adenocarcinoma [5]

\begin{tabular}{|c|c|c|}
\hline $\begin{array}{l}\text { Resectability } \\
\text { status }\end{array}$ & Criteria & $\begin{array}{l}\text { Median survival } \\
\text { (months) }\end{array}$ \\
\hline Resectable & $\begin{array}{l}\text { No distant metastases } \\
\text { No radiographic evidence of SMV and portal vein abutment, distortion, tumor thrombus, or encasement } \\
\text { Clear fat planes around the celiac axis, hepatic artery, and SMA }\end{array}$ & $20-24$ \\
\hline $\begin{array}{l}\text { Borderline } \\
\text { resectable }\end{array}$ & $\begin{array}{l}\text { No distant metastases } \\
\text { Venous involvement of the SMV/portal vein demonstrating tumor abutment with or without impingement and } \\
\text { narrowing of the lumen, encasement of the SMV/portal vein but without encasement of the nearby arteries, or } \\
\text { short segment venous occlusion resulting from either tumor thrombus or encasement but with suitable vessel } \\
\text { proximal and distal to the area of vessel involvement, allowing for safe resection and reconstruction } \\
\text { GDA encasement up to the hepatic artery with either short segment encasement or direct abutment of the hepatic } \\
\text { artery without extension to the celiac axis }\end{array}$ & Resected, $\sim 20$ \\
\hline & Tumor abutment of the SMA not to exceed $>180^{\circ}$ of the circumference of the vessel wall & Unresected, $\sim 11$ \\
\hline $\begin{array}{l}\text { Locally } \\
\text { advanced }\end{array}$ & $\begin{array}{l}\text { Head: no distant metastases, SMA encasement exceeding }>180^{\circ} \text { or any celiac axis abutment, unreconstructible } \\
\text { SMA/portal vein occlusion/encasement, extensive hepatic artery involvement, aortic invasion or encasement } \\
\text { Body: no distant metastases, SMA or celiac axis encasement }>180^{\circ} \text {, unreconstructible SMV/portal occlusion, } \\
\text { aortic invasion } \\
\text { Tail: no distant metastases, SMA or celiac axis encasement }>180^{\circ} \\
\text { All: metastases to lymph node beyond the field of resection }\end{array}$ & $9-15$ \\
\hline Metastatic & Any presence of distant metastases & $4-6$ \\
\hline
\end{tabular}

$S M V$ superior mesenteric vein, $S M A$ superior mesenteric artery, GDA gastroduodenal artery

resection with induction therapy. One study from MDAH showed that lymph node positivity was reduced to $38 \%$ with induction chemoradiation, pathological complete response (pCR) rate was $1 \%$, and the rate of margin-negative resections was $89 \%$ [6]. In comparison, the recently published long-term results of the US Intergroup/RTOG 9704 study of resectable pancreatic cancers treated with adjuvant chemoradiation demonstrated positive lymph nodes in $67 \%$ of patients and an R0 resection rate of only $40 \%$ [7]. Incorporating upfront therapy also increases the likelihood that patients will receive the needed chemotherapy and radiation therapy to treat microscopic disease, without any delays from post-operative recovery [8]. Specific benefits of the incorporation of neoadjuvant radiation therapy include the ability to treat visible disease and target radiation to the vessel locations which qualified patients to be borderline resectable in the first place. It potentially targets an intact vascular supply for better oxygenation and may allow for smaller radiation portals. If surgery is not performed, it also allows for "definitive" local therapy in a timely fashion. The major critique of neoadjuvant therapy in pancreatic cancer is that it delays surgery and, thus, potentially eliminates a chance of cure in eligible patients.

Given the potential advantages of neoadjuvant treatment for pancreatic cancer, it has been increasingly utilized in the past two decades. Below, we review the data regarding neoadjuvant
Fig. 1 Examples of borderline resectable pancreatic cancer. Left, tumor abutment of the portal vein; right, tumor abutment of the superior mesenteric artery $<180^{\circ}$ circumference

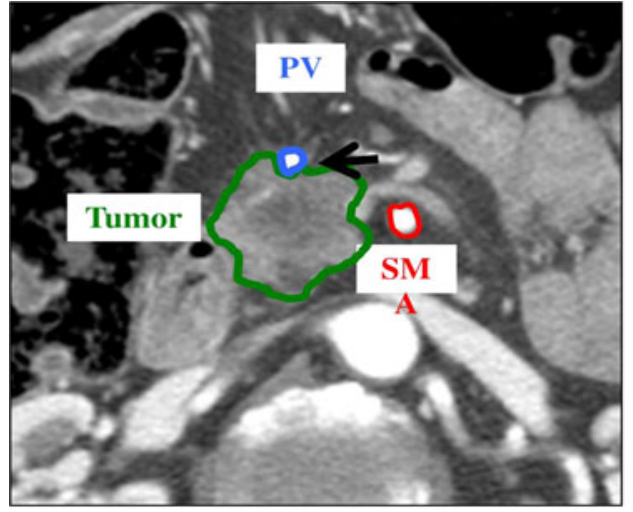

PORTAL VEIN (PV) ABUTMENT

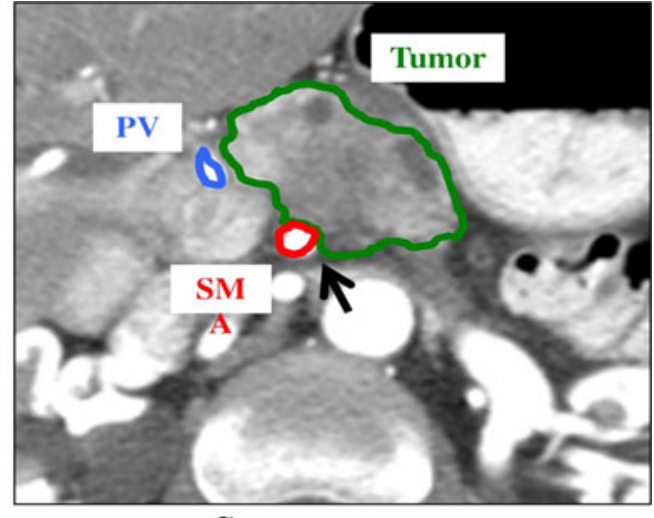

SUPERIOR MESENTERIC ARTERY (SMA) ABUTMENT 
therapy for potentially resectable and borderline resectable pancreatic cancer with a survey of prospective, retrospective, imaging, and pathological studies.

\section{Predictors of response to therapy}

Attention has been focused on the histolopathologic response to induction therapy and subsequent patient outcomes. Tumor response has been graded according to one of three systems: Ishikawa, Evans criteria, and the College of American Pathologists (CAP); while the Ishikawa criteria are still implemented in Japan, the Evans and CAP criteria are the most widely used elsewhere [9-11]. The Ishikawa criteria grade response based on severely degenerative cancer cells (SDCCs), in which grade 1 is $<33 \%$ SDCCs, grade 2 is $33-66 \%$ SDCCs, and grade 3 is $\geq 67 \%$ SDCCs [9]. The Evans criteria grade response on a scale from I to IV by assessing the percentage of viable tumor cells in the post-treatment surgical specimen [10]. Increasing grade represents less viable tumor: grade I, no or little $(<10 \%)$ tumor cell destruction; grade IIa, 10-50\% tumor cell destruction; grade IIb, 50-90\% tumor cell destruction; grade III, few $(<10 \%)$ viable tumor cells; and grade IV, no viable tumor [10]. Similarly, the CAP system uses a fourtier system: grade 0 , no viable residual tumor $(\mathrm{pCR})$; grade 1 , marked response (minimal residual tumor with single cells or cell groups); grade 2, moderate response (residual cancer outgrown by fibrosis); and grade 3 , poor or no response [11].

Multiple studies have attempted to correlate patient outcomes with histological response following neoadjuvant therapy for resectable and borderline resectable pancreatic cancer. The great majority of these studies have been retrospective, and one is based on a prospective dataset [12-17]. The largest of these analyses was performed at MD Anderson by Zhao and colleagues who analyzed 442 patient specimens by the Evans criteria [12]. Patients had undergone neoadjuvant therapy (5-FU, gemcitabine, or chemoradiation) followed by pancreatic resection from 1995 to 2010 [10]. Post-treatment cancer specimens were identified as stage I (14 with ypT1 and 1 with ypT2 disease) and stage IIA disease ( 85 with ypT3 disease). Eleven cases $(2.9 \%)$ had a pCR. The study notes that the survival of patients with $\mathrm{pCR}$ to neoadjuvant therapy was significantly longer than those who had residual disease (ypT1-T3). While specific survival numbers are not provided in the published data, the KaplanMeier estimates suggest a disease-specific survival (DSS) of $100 \%$ at 10 years for patients with a pCR following neoadjuvant therapy, whereas for stage I and IIA diseases following neoadjuvant therapy, DSS was approximately $70 \%$ and $35 \%$, respectively. Such pathological responses probably reflect the biology of each patient's cancer.
Similar to the previous study, White and colleagues at Duke performed an analysis of 102 patients with potentially resectable tumors treated since 1994 with neoadjuvant chemoradiation (5-FU-based with 50.4 Gy of radiation), 54 (53\%) of whom underwent subsequent resection [13]. The pathological specimens were analyzed and scored according to the Evans criteria [10]. An impressive pathologic response was noted in which $73 \%$ of patients had R0 resections, $70 \%$ of patients had lymph node-negative resections, and $6 \%$ had a pCR to neoadjuvant therapy. Tumor fibrosis was extensive in most specimens ( $76 \%$ ), and necrosis was noted in $1 / 3$ of patients. There was no relationship between tumor necrosis and gross tumor size, initial resectability, or residual tumor load. An immunohistochemical analysis was also performed on the residual tumor specimens and revealed p53 overexpression in almost half of all specimens (44\%), and epidermal growth factor (EGFR) staining was present in $5 \%$ of residual carcinomas. Survival was improved in patients with a small to moderate residual tumor load versus those with a large amount of residual tumor $(p=0.02)$. The degree of fibrosis was not associated with survival, and tumor necrosis was associated with a worse survival $(p<0.02)$.

\section{Literature regarding treatment}

\section{Prospective trials}

\section{Neoadjuvant chemotherapy alone}

Single-modality early-phase trials have primarily addressed the role of chemotherapy alone as neoadjuvant therapy for pancreatic cancer (Table 2) [18-21]. Four phase II studies have studied either gemcitabine alone or combination chemotherapy with gemcitabine [18-21]. The resection rate in this group of patients varies widely between 33 and $89 \%$, and the $\mathrm{R} 0$ resection rate is $75 \%$. Disease-free survival (DFS) ranges between 9.2 and 12 months, and overall survival (OS) in resected patients 18 months (range, 9.9 to 26.5 months). Palmer and colleagues compared gemcitabine alone versus gemcitabine + cisplatin as neoadjuvant therapy for resectable and borderline resectable patients [18]. The combination of gemcitabine and cisplatin led to an improved resection rate versus gemcitabine alone ( $70 \%$ vs. $38 \%$, respectively), as well as an improved median overall survival (15.6 months vs. 9.9 months). One caveat to these studies is that the number of patients enrolled is low (range, 12-28).

\section{Neoadjuvant radiation alone}

A phase I trial studying carbon ion radiotherapy has been completed in Japan (Table 2) [22]. The authors investigated escalating doses of carbon ions from 30 to $36.8 \mathrm{~Gy}$ as 
Table 2 Prospective single-modality therapy studies of neoadjuvant therapy for resectable and borderline resectable pancreatic cancer

\begin{tabular}{|c|c|c|c|c|c|c|c|c|}
\hline Author (year) & $\begin{array}{l}\text { Number of } \\
\text { patients }\end{array}$ & $\begin{array}{l}\text { Res/BR/Both } \\
\text { (criteria) }\end{array}$ & Total RT & Frac dose & Chemo & $\begin{array}{l}\text { Resection } \\
(\%)\end{array}$ & $\begin{array}{l}\mathrm{R} 0 \\
(\%)\end{array}$ & Median OS (months) \\
\hline \multirow[t]{2}{*}{ Palmer (2007) } & 24 & Both (Consensus) & \multirow[t]{2}{*}{ NA } & \multirow[t]{2}{*}{ NA } & Gem $\left(1,000 \mathrm{mg} / \mathrm{m}^{2}\right.$ weekly $)$ & 38 & 75 & $9.9(1$ year, $42 \%)$ \\
\hline & 26 & Both (Consensus) & & & $\begin{array}{l}\text { Gem }\left(1,000 \mathrm{mg} / \mathrm{m}^{2} \text { weekly }\right) \\
\quad+\operatorname{Cis}\left(25 \mathrm{mg} / \mathrm{m}^{2}\right)\end{array}$ & 70 & 75 & $15.6(1$ year, $62 \%)$ \\
\hline Heinrich (2008) & 28 & Both (Consensus) & NA & NA & $\begin{array}{l}\text { Gem }\left(1,000 \mathrm{mg} / \mathrm{m}^{2} \text { twice weekly }\right) \\
\quad+\text { Cis }\left(50 \mathrm{mg} / \mathrm{m}^{2}\right)\end{array}$ & 89 & 80 & 26.5 \\
\hline Sahora (2011) & 15 & BR (Consensus) & NA & NA & $\begin{array}{l}\text { Gem }\left(900 \mathrm{mg} / \mathrm{m}^{2} \text { weekly }\right) \\
\quad+\mathrm{Ox}\left(60 \mathrm{mg} / \mathrm{m}^{2}\right)\end{array}$ & 47 & 69 & $\begin{array}{l}22 \text { resected, } 12 \\
\text { no surgery }\end{array}$ \\
\hline Sahora (2011) & 12 & BR (Consensus) & NA & NA & $\begin{array}{l}\operatorname{Gem}\left(900 \mathrm{mg} / \mathrm{m}^{2} \text { weekly }\right) \\
\quad+\operatorname{Tax}\left(35 \mathrm{mg} / \mathrm{m}^{2}\right)\end{array}$ & 33 & 87 & $\begin{array}{l}16 \text { resected, } 12 \\
\text { no surgery }\end{array}$ \\
\hline Lee (2012) & 18 & BR (Consensus) & NA & NA & $\begin{array}{l}\text { Gem }\left(1,250 \mathrm{mg} / \mathrm{m}^{2} \text { every }\right. \\
3 \text { weeks })+ \text { Cap }\left(950 \mathrm{mg} / \mathrm{m}^{2}\right)\end{array}$ & 61 & 82 & $\begin{array}{r}16.6 \text { (surgery } 23.1 \\
\text { no surgery } 13.2 \text { ) }\end{array}$ \\
\hline Shinoto (2012) & 26 & Res (Consensus) & $30-36.8$ & Carbon ions & None & 81 & 90 & $\begin{array}{c}18.6(1 \text { year } 69 \% \\
3 \text { years } 42 \% .5 \\
\text { years, } 42 \%)\end{array}$ \\
\hline
\end{tabular}

Res resectable, $B R$ borderline resectable, $R T$ total radiation dose, Frac dose fractionated radiation dose, Gem gemcitabine, Cis cisplatin, $O x$ oxaliplatin, Tax taxotere, Cap capecitabine, $N A$ not applicable

neoadjuvant therapy for resectable pancreatic cancer. The resection rate was high $(81 \%)$ as was the $\mathrm{R} 0$ resection rate $(90 \%)$. In this select group of patients, local control was $100 \%$, DFS was 6.2 months (40\% 1-year DFS, $23 \% 3$ and 5-year DFS), and OS was 18.6 months (69 \% at 1 year, $42 \%$ at 3 and 5 years). In the subset of patients who underwent surgery, the 5-year survival was an impressive $52 \%$. Intriguingly, grade $3 / 4$ toxicity was low at $8 \%$. Concurrent chemotherapy was not administered with the radiation. These exciting results suggest a role for further investigational trials on this subject with the caveat that the availability of this technology remains limited.

\section{Induction chemotherapy prior to neoadjuvant chemoradiation}

Induction chemotherapy prior to neoadjuvant chemoradiation has also been investigated (Table 3) [23-26]. Most of these trials have studied induction gemcitabine-based chemotherapy. Resection rates range from 18 to $71 \%$ with induction chemotherapy, and $\mathrm{R} 0$ resection rates vary between 50 and $96 \%$. The largest of these studies was completed by Varadachary and colleagues and studied the use of gemcitabine and cisplatin prior to neoadjuvant chemoradiation with gemcitabine and 30 Gy of external beam radiation therapy (EBRT) [24]. In their 90-patient trial, a median DFS of 13.2 months and an OS of 17.4 months were observed. As with previously described data, the survival rate of resected patients was statistically greater than that of unresected patients (28.3 months vs. 10.5 months) in this series. Pipas and colleagues investigated the role of induction cetuximab, an epidermal growth factor receptor antibody, prior to neoadjuvant chemoradiation with gemcitabine [26]. They reported a relatively high pathologic complete response rate $(8 \%)$ in the post-operative specimen, with similar survival results as seen in previous trials. However, EGFR receptor status was not predictive of response to therapy.

\section{Neoadjuvant chemoradiation}

Neoadjuvant chemoradiation has been extensively studied in prospective phase I and II clinical trials and prospective database studies (Table 4) [6, 17, 25, 27-41]. Gemcitabine and either 5-FU or capecitabine have been the primary chemotherapy used, while radiation doses have mostly been up to $50.4 \mathrm{~Gy}$ in $1.8 \mathrm{~Gy} /$ fraction, though some have used 30 to $36 \mathrm{~Gy}$ in $3 \mathrm{~Gy} /$ fraction. Because the standard definition of "borderline resectable" was not widely applied until the mid2000 s, trials initiated prior to this date may not have had the $\mathrm{NCCN} /$ Consensus guidelines used in their accrual. However, data from these trials are interpreted as closely as possible using the NCCN/Consensus definitions for resectability.

Evans and colleagues from MD Anderson Hospital published the results of their prospective phase II trial of neoadjuvant chemoradiation for resectable pancreatic cancer in 2008 [6]. Their treatment regimen consisted of concurrent weekly gemcitabine $\left(400 \mathrm{mg} / \mathrm{m}^{2}\right)$ and $30 \mathrm{~Gy}$ in ten fractions followed by five additional doses of weekly gemcitabine at the same dose. Of their 86 enrolled patients, 73 (85\%) underwent surgical resection, and $64(74 \%)$ had a successful pancreatectomy. The median survival of their entire cohort was 22.7 months, with a statistically better survival in patients who underwent pancreatectomy (34 months vs. 7 months, $p<0.001)$. This improved survival was dramatically demonstrated in the rates of 5-year survival: $36 \%$ in resected patients versus $0 \%$ in unresected patients. Progression-free survival 
was 28.6 months in resected patients. Local recurrence was only $11 \%$ in patients who underwent successful surgery. One unique finding from an earlier prospective database analysis from MD Anderson was the influence of intraoperative radiation therapy (IORT) [42]. They specifically identified that in $56 \%$ of patients receiving IORT in their patient population, IORT did not provide a survival benefit, though no local recurrences were observed with the addition of IORT to full dose (50.4-54.0 Gy) EBRT.

A study by Landry and colleagues compares induction chemotherapy followed by neoadjuvant chemoradiation versus neoadjuvant chemoradiation alone [25]. Both borderline resectable and locally advanced patients were enrolled in this study. In this randomized trial, overall resection rate, R0 resections, DFS, and OS were higher in patients treated with neoadjuvant chemoradiation alone.

Surgical results from a summary of these trials in Table 6 show a median resectability rate of $57 \%$ (range, 18 to $100 \%$ ) and a median R0 resection rate of $85 \%$ (range, 33 to $100 \%$ ). DFS and OS vary widely as represented in Table 6. Reported 1-year DFS ranges from 42 to $59 \%$ for resected patients, and 2-year DFS ranges from 33 to $43.7 \%$. Extended OS ( $>2$ years) for patients with resectable disease ranges from 28 to $58 \%$ in this collection of randomized trials $[6,27,28,33,35]$. Grade $3 / 4$ toxicities range from 20 to $66 \%$, while reported surgical complications range from 0 to $50 \%$. Randomized prospective data is limited for neoadjuvant therapy in pancreatic cancer.

One factor that may result in differences between these trials is the varied implementation of adjuvant therapy. Due to the variety of agents and cycles used, it is difficult to reliably interpret data from these trials in their use of adjuvant therapy.

In general, prospective data appears to support the use of neoadjuvant therapy in resectable and borderline resectable tumors in identifying patients more likely to present with metastatic disease shortly after surgery and, hence, sparing them from significant surgical side effects. Overall and R0 resection rates appear to be favorable with relatively low surgical complications and reduced pancreatic leak rates [5]. Many surgeons agree that surgery following chemotherapy or chemoradiation for pancreatic cancer does not increase surgical morbidity if it is performed within a reasonable period (approximately 4-8 weeks) of the completion of radiation. While this data is extremely encouraging to consider the standardization of neoadjuvant chemoradiation in resectable and borderline resectable pancreatic cancer, a large randomized, prospective phase III clinical trial will be necessary to answer this question.

\section{Retrospective data}

Multiple retrospective series have been performed on the topic of neoadjuvant therapy for resectable pancreatic cancer 


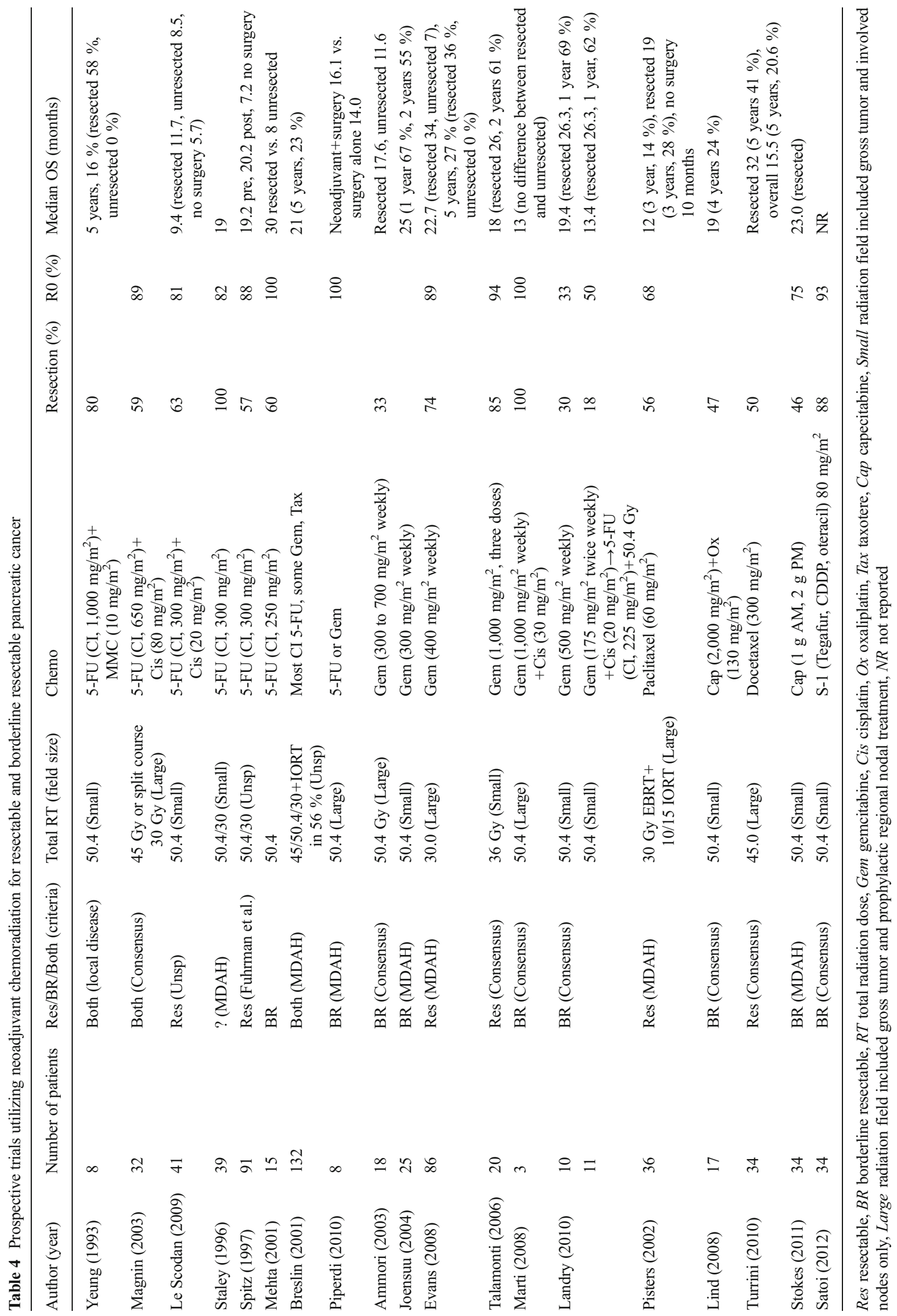




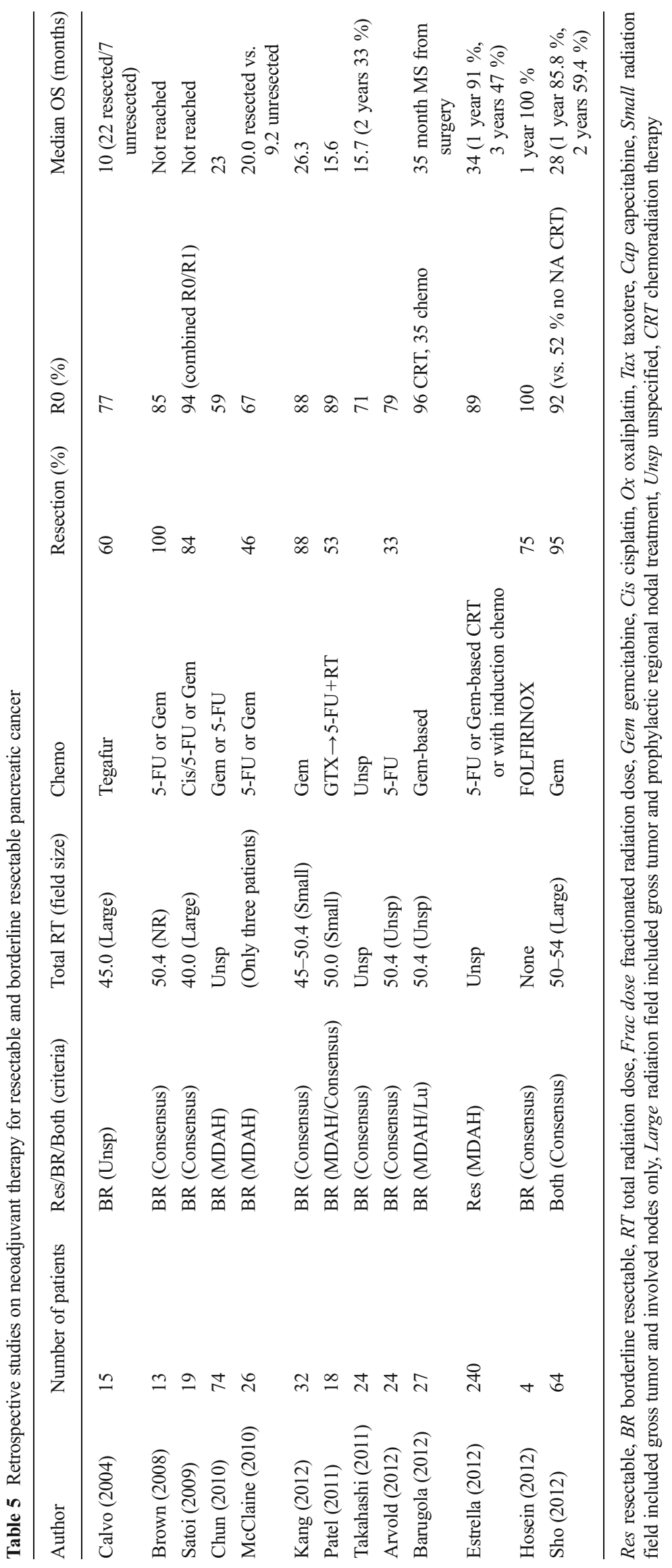


Table 6 Ongoing prospective clinical trials with neoadjuvant chemotherapy alone in resectable and borderline resectable pancreatic cancer

\begin{tabular}{lllll}
\hline Clinical trial number & Phase & Neoadjuvant investigational therapy & Location & Date opened \\
\hline NCT01442974 & & Gem+Abraxane & Spain & January 2011 \\
NCT01456585 & I & Gem+CP-870,893 & University of Pennsylvania & April 2012 \\
NCT00892242 & I & Zoledronic acid & Washington University (St. Louis) & December 2009 \\
NCT01431794 & I/II & LDE-225 (hedgehog inhibitor)+Gem & Johns Hopkins & September 2011 \\
NCT01088789 & II & Neoadjuvant GM-CSF secreting vaccine & Johns Hopkins & April 2010 \\
NCT01660711 & II & FOLFIRINOX & University of Chicago & July 2012 \\
NCT01298011 & II & Gem+Abraxane & Celegene Corp (USA) & May 2011 \\
NCT00733746 & II & Gem+Tarceva & National Cancer Institute & April 2009 \\
NCT01150630 & II/III & Gem +/- Xeloda and epirubicin and cisplatin & Italy & May 2010 \\
NCT00727441 & III & Neoadjuvant GM-CSF secreting vaccine & Johns Hopkins & July 2008 \\
NCT01521702 & III & Gem+oxaliplatin & France & December 2011 \\
NCT01314027 & III & Gem+oxaliplatin & Switzerland & September 2009 \\
\hline
\end{tabular}

Gem gemcitabine, FOLFIRINOX combination chemotherapy of 5-FU, leucovorin, oxaliplatin, and irinotecan

[43-55]. Historically, retrospective studies have focused on locally advanced disease, but more recent data has included primarily resectable cancers. Most studies have included chemoradiation, but limited data on chemotherapy alone is also available $[49,54]$.

A review of 13 retrospective studies from 2004 to 2012 demonstrated that the majority of patients in whom neoadjuvant therapy was analyzed pertained primarily to borderline resectable disease (Table 5) [43-55]. As a whole, the median number of patients included in these studies was 22. Most patients received either 5-FU or gemcitabine-based therapy, and the most common radiation therapy regimen was to 50.4 Gy in 1.8-Gy fractions. The median resection rate following neoadjuvant therapy was $68 \%$; the median R0 rate was $89 \%$ with a pCR rate of approximately $9 \%$. In a retrospective analysis by Barugola et al., the R0 rate was significantly in patients who received neoadjuvant chemoradiation versus chemotherapy alone ( $96 \%$ vs. $35 \%$, respectively) [52]. Local control following chemoradiation ranged between 78 and $89 \%$.

Overall survival and disease-free survival were reported in most studies [43, 46-50, 52-55]. One-year DFS ranged from 51 to $88 \%$, while 1 -year OS ranged from 85.8 to $100 \%$. Median OS for resected patients ranged from 15.3 to 35 months. In two studies, a statistically significant difference in overall survival was noted between resected and unresected patients following neoadjuvant therapy (median, 21 months vs. 8.1 months, respectively). Data from the largest of the retrospective analyses was completed by Estrella et al. and showed a survival benefit for neoadjuvant therapy versus adjuvant therapy for resectable disease (33.5 months vs. 26.4 months, $p=0.04$ ) [53].

Neoadjuvant therapy was also reported to be safe, though with grade $3 / 4$ toxicity rates of 22 to $66 \%$. Surgical complication rates ranged between 24 and $67 \%$. One study noted that neoadjuvant therapy led to decreased rates of pancreatic fistula and shorter hospital stays [55]. This is in contrast to Kang et al. who reported higher rates of second blood transfusions and longer hospital stays with neoadjuvant therapy [48].

Surveillance, Epidemiology, and End Results (SEER) databases allow for a review of patient charts as reported to a central database. Two SEER database analyses have been completed in the USA [56, 57].

The larger of these SEER studies was completed by Stessin in 2008 [56]. They identified patients treated from 1993 to 2003 with neoadjuvant radiation therapy for pancreatic cancer. They removed patients with stage III/IV disease to limit the contribution of unresectable disease. Of the 3,885 patients that met their initial criteria, $70(2 \%)$ were treated with neoadjuvant chemoradiation, 1,478 (38\%) had adjuvant radiation, and 2,337 (60\%) had no radiation as part of their treatment. The authors' major findings support an improved median survival of 23 months with adjuvant radiation versus a median survival of 14 months in patients without radiation (hazard ratio (HR) $0.55, p<0.01$ ).

A more recent SEER database analysis was completed by Artinyan in 2011 and reviewed patients as part of the California Cancer Surveillance Program [57]. A comparative analysis was performed between patients treated with neoadjuvant therapy and those treated with adjuvant therapy. A far greater number of patients were included in the adjuvant therapy group (419 patients) than in the neoadjuvant therapy group (39 patients). As with the previous SEER database study, the overall survival was statistically greater for patients treated with neoadjuvant therapy (33.8 months vs. 19.0 months, $p=0.003)$. When controlling for lymph node status, tumor extension, and the addition of radiation, neoadjuvant 
chemotherapy was still associated with improved overall survival (HR for death $0.57, p=0.013$ ).

A Japanese survey of pancreatic cancer patient outcomes in 146 institutions was performed and showed similar survival patterns as the aforementioned SEER database analyses [58]. While retrospective and difficult to control for the heterogeneity of cases, the SEER database analyses provide further hypothesis-generating data along with the previously noted retrospective analyses for the use of neoadjuvant therapy.

\section{Meta-analyses of neoadjuvant therapy data}

Given the substantial amount of data accumulated, predominantly in the last two decades, on the utilization of neoadjuvant therapy for pancreatic adenocarcinoma, it comes as no surprise that multiple meta-analyses have been published in an attempt to fully digest this data [59-62]. Laurence and colleagues reviewed 19 cohort studies conducted between 1985 and 2007 [59]. Studies were selected to include all categories of patients which included initially unresectable disease. The neoadjuvant chemoradiation schedule was predominantly comprised of 5-FU- or gemcitabine-based chemotherapy and radiation typically prescribed to a dose of 45-50.4 Gy in 1.8to 2.0-Gy fractions. A total of 2,148 patients were included in this analysis: neoadjuvant chemoradiation was administered to 901 patients (469 of which went on to receive subsequent surgery) who were compared to 982 who did not receive neoadjuvant therapy (811 underwent resection). It should be noted that only 4 of the studies analyzed included resectable patients; the remaining 15 had unresectable and borderline resectable patients. The authors note that the survival of patients with initially unresectable disease is improved with the addition of neoadjuvant therapy but, unfortunately, do not separate the survival of borderline resectable patients in this analysis. This may be due to the great heterogeneity seen in patients treated during this time period and the various definitions of borderline (or potentially) resectable cancer utilized.

The largest meta-analysis we identified was published by Gillen in 2010 [61]. This study included phase I and II clinical trials, cohort studies, and retrospective case series. In all, they were able to compile patients from 78 prospective studies and 33 retrospective studies. Neoadjuvant chemotherapy was utilized in $96.4 \%$ of these studies (mostly gemcitabine- (46\%) and 5-FU-based (54\%) treatments), and radiation therapy was used in $93.7 \%$ of studies (most commonly between 45 and 50.4 Gy in 1.8-Gy fractions). Though their group included an array of patients, they were able to dichotomize patients into two groups: group 1, patients that were initially resectable, and group 2, initially unresectable disease. Imaging outcomes (by Response Evaluation Criteria in Solid Tumors (RECIST)), resectability, morbidity, toxicity, and survival were reported. Neoadjuvant therapy led to an imaging complete response (CR) in $3.9 \%$ of patients, partial response (PR) in $29.1 \%$, stable disease in $43.9 \%$, and progressive disease (PD) in $20.8 \%$. Overall grade $3 / 4$ toxicity in $29.4 \%$ of neoadjuvant therapy patients was evenly distributed between groups 1 and 2 (26.3 and $31.1 \%$, respectively). Resection was completed in $75.5 \%$ of group 1 patients and $32.8 \%$ of group 2 patients. In all resectable cases, however, R0 resections were accomplished in a vast majority of cases, with $82.1 \%$ of group 1 and $79.2 \%$ of group 2 patients. It should be noted that perioperative morbidity was higher in group 2 patients, $39.1 \%$ versus $26.7 \%$, as was in-hospital mortality, $7.1 \%$ versus $3.9 \%$. Overall survival was strongly correlated to resection. In group 1 patients, the median survival in resected patients was 23.3 months versus 8.4 months for those unresected. Similar results were seen in group 2 patients (20.4 months vs. 10.2 months). Though the data from metaanalyses can often be difficult to interpret given the heterogeneity of patients between trials as well as treatment differences that occur with time, this data strongly suggests that neoadjuvant therapy may not only help achieve margin-negative resections but also identify patients that may otherwise not benefit from upfront resection.

\section{Imaging outcomes}

Recently, multiple studies have sought to quantify imaging responses to neoadjuvant therapy for pancreatic cancer patients [63, 64]. Chuong and colleagues performed a small retrospective analysis of neoadjuvant gemcitabine, taxotere, and capecitabine, followed by radiation ( $50.4 \mathrm{~Gy}$, predominantly intensity modulated radiation therapy (IMRT)) and 5-FU for borderline resectable pancreatic cancer patients [63]. The authors analyzed whether tumor response to neoadjuvant therapy was best assessed using one-, two-, or threedimensional measurements on follow-up CT scans. Fourteen patients were included, and the results demonstrated that all measurement dimensions were concordant to one another, with even one-dimensional measurements of tumor response being equal to volumetric measurements. Further, the authors report that responses were equivalent whether utilizing the WHO, RECIST, or volumetric methods in all but one patient. All 14 patients in this analysis underwent surgical resection, with 12 (86\%) achieving an R0 resection and $2(14 \%)$ with microscopically positive margins.

A larger retrospective analysis was completed at the MD Anderson Cancer Center [64]. In this report, 129 patients with borderline resectable pancreatic cancer as defined by the AHPBA/SSO/SSAT or MD Anderson criteria were included. Patients underwent neoadjuvant therapy with one of two treatment regimens: (1) gemcitabine-based systemic chemotherapy followed by chemoradiation to $30 \mathrm{~Gy}$ in ten fractions or 50.4 Gy in 1.8-Gy fractions along with concurrent gemcitabine, 5-FU, or capecitabine; and (2) chemoradiation alone. A pre- 
treatment $\mathrm{CT}$ scan with oral and intravenous contrast was performed, as was a post-neoadjuvant therapy CT scan. Response criteria followed the modified RECIST criteria: PD was identified as new metastatic foci or an increase in greatest dimension by $\geq 20 \%$, a PR was defined as a decrease of $\geq 30 \%$ in greatest dimension, CR was disappearance of the primary tumor, and stable disease (SD) was tumor growth $<20 \%$ or shrinkage $<30 \%$. This study demonstrated a lack of significant $\mathrm{CR}$ by imaging criteria [64]. Of the 122 patients assessed for response using the AHPBA/SSO/SSAT criteria, only 1 patient was downstaged, 98 patients remained the same (80\%), and 23 patients had upstaging (19\%). This does not imply that the tumor did not decrease in size, only that the consensus surgical stage was not altered by the treatment. Of the treated patients, only patients with a PR or SD underwent resection. The single patient with disease downstaging underwent resection, as did 82 of the 98 patients with SD (84\%). RECIST response was not associated with a longer median overall survival, but surgically resected patients had a median overall survival of 33.0 months as opposed to 12.0 months in those that did not undergo resection. Further, an $\mathrm{R} 0$ resection was accomplished in $81 / 101$ patients $(80 \%)$ in whom metastatic disease was not observed following neoadjuvant therapy. The authors conclude that despite a lack of radiographic response in this patient population, aggressive resection should be attempted in borderline resectable patients following neoadjuvant therapy in the absence of locally progressive or metastatic disease.

The use of FDG-PET scanning is an area of active research in pancreatic cancer. This modality continues to be explored for its possible role in determining treatment response as retrospective analyses demonstrate that it may have clinical utility in identifying tumor response and potential resectability [65-69]. As a whole, these studies demonstrate improved survival and resectability in patients who achieve a PET response, defined as $\geq 50 \%$ reduction in PET avidity. However, they are all limited by their small patient size and lack of a numerical SUV for universal implementation. Testing the use of PET scans in a large prospective trial will help determine the clinical accuracy of this imaging modality for pancreatic cancer.

\section{Pathological correlation with patient outcome}

While the rationale for neoadjuvant therapy in pancreatic cancer would suggest that most patients with localized, surgically resectable disease will be benefited, there is a small group of patients that does not benefit from this treatment modality. Histopathologic analyses have been performed to assess whether a subset of patients that will not benefit from this treatment may be identified. Further, predictive markers have also been studied to answer this question.
Limited studies exist regarding predictive markers of patient outcome in pre-treated patient samples. A study by Preis and colleagues from Dartmouth Medical Center studied pancreatic cancer patients treated with neoadjuvant gemcitabinebased chemoradiation followed by planned surgical resection [70]. They investigated the correlation of microRNA expression, as characterized by in situ hybridization and immunohistochemistry, and patient outcomes. They found that lower levels of miRNA10b expression correlated with an improved response to multimodality neoadjuvant therapy, an improved likelihood of surgical resection, delayed time to metastases, and increased survival. However, this study is limited by its small sample size (ten patients) uncommon use of this test, and needs to be reproduced in a prospective setting.

Data from Iacobuzio-Donohue and colleagues demonstrates that positive immunolabeling of DPC4 (deleted in pancreatic cancer) on rapid autopsy specimens may be more locally destructive tumors and less metastatic disease, whereas loss of DPC4 labeling was associated with a higher burden of metastatic disease and less locally advanced disease [71]. Further research on this topic will elucidate whether this marker may be used to prospectively consider intensification of radiation therapy for DPC4 wild-type cases and intensification of chemotherapy for DPC4 mutated cases, prior to surgical research for initially non-metastatic disease.

CA 19-9 is a sialylated Lewis A blood group antigen commonly associated, but not specific for, pancreatic tumors. It should be obtained in the preoperative setting with a normalized bilirubin, as well as in the post-operative setting to monitor for treatment response [8]. Katz et al. investigated the role of CA 19-9 in two phase II clinical trials for neoadjuvant therapy (gemcitabine-based chemoradiation) for surgically resectable patients [72]. In the pre-treatment setting, patients with a CA 19-9 in the normal range had a more favorable survival than those with an elevated CA 19-9 $(p=0.02)$, though this was not maintained when evaluating only patients who underwent a pancreaticoduodenectomy $(p=0.08)$. At restaging, a CA 19-9 cutoff of $61 \mathrm{U} / \mathrm{mL}$ was proposed as the optimal cutoff value that maximized both sensitivity (72\%) and specificity (69\%) for completing all therapy. A decreased CA 19-9 between pre-treatment and re-staging was correlated with more favorable survival (25.7 months vs. 10.4 months, $p=0.01$ ), and these patients were more likely to undergo surgery ( $77 \%$ vs. $42 \%, p=0.02)$ [72]. There was no correlation between treatment effect in the surgical specimen and CA 19-9 change over the course of induction therapy. Further study is necessary prior to utilizing this marker in routine clinical selection of treatment options following induction therapy, but it is suggestive that CA 19-9 may help guide therapeutic strategies.

In an effort to better clarify which patients may need more aggressive therapy following surgery, the prognostic significance of lymphovascular invasion, perineural invasion (PNI), 
Table 7 Ongoing prospective clinical trials with neoadjuvant chemoradiation in resectable and borderline resectable pancreatic cancer

\begin{tabular}{|c|c|c|c|c|}
\hline $\begin{array}{l}\text { Clinical trial } \\
\text { number }\end{array}$ & Phase & Neoadjuvant investigational therapy & Location & Date opened \\
\hline NCT01446458 & I & FOLFIRINOX followed by SBRT ( 12 Gy $\times 3$ fractions) & Emory University & November 2011 \\
\hline NCT01068327 & I & $\begin{array}{l}\text { Gem+leucovorin }+5 \text {-FU followed by SBRT } \\
\text { (five fractions) with concurrent nelfinavir }\end{array}$ & University of Nebraska & November 2007 \\
\hline NCT01027221 & $\mathrm{I} / \mathrm{II}$ & Low-dose radiation (one fraction of $0.5,2.0$, or $5.0 \mathrm{~Gy}$ ) & Germany & November 2009 \\
\hline NCT01458717 & II & $\begin{array}{l}\text { CRT ( } 54 \mathrm{~Gy}+\mathrm{Gem} \text { ), followed by surgery vs. } \\
\text { surgery followed by adjuvant } 54 \mathrm{~Gy}+\mathrm{Gem}\end{array}$ & Korea & November 2011 \\
\hline NCT01333332 & II & CRT with Xeloda and standard fraction RT & University of Virginia & August 2010 \\
\hline NCT01397019 & II & FOLFIRINOX followed by 50.4 Gy RT & Denmark & October2011 \\
\hline NCT01661088 & II & FOLFIRINOX followed by concurrent Gem +50.4 Gy RT & University of Michigan & June 2011 \\
\hline NCT01531712 & II & $\begin{array}{l}\text { Gem+oxaliplatin }+ \text { Tarceva followed by Gem+Tarceva }+ \\
\text { radiation }(50.4 \text { Gy) }\end{array}$ & Spain & July 2011 \\
\hline NCT01591733 & II & $\begin{array}{l}\text { FOLFIRINOX followed by } 5 \text { days of proton radiation } \\
\text { (dose not specified) }\end{array}$ & Massachusetts General Hospital & May 2012 \\
\hline NCT01560949 & II & FOLFIRINOX followed by concurrent Gem +50.4 Gy RT & MD Anderson & June 2012 \\
\hline NCT01470417 & II & $\begin{array}{l}\text { Abraxane }+ \text { Gem followed by concurrent radiation } \\
\text { (dose not specified) and chemotherapy (not specified) }\end{array}$ & University of Florida & October 2011 \\
\hline NCT01240304 & II & $\begin{array}{l}\text { Gem and radiation ( } 7.0 \mathrm{~Gy} / \text { fraction) alternating every } \\
24 \mathrm{~h} \text { for a total of ten treatments (total } 35 \mathrm{~Gy} \text { RT) }\end{array}$ & University of Arkansas & November 2010 \\
\hline NCT01677988 & II & FOLFIRINOX $\rightarrow$ Xeloda + radiation (dose not specified) & $\begin{array}{l}\text { Medical University of } \\
\text { South Carolina }\end{array}$ & July 2012 \\
\hline NCT00456599 & II & Gem+oxaliplatin+radiation (30 Gy in ten fractions) & University of Michigan & April 2007 \\
\hline NCT01389440 & II & Gem + Tarceva followed by Gem + Tarceva +radiation ( 45 Gy) & Spain & May 2011 \\
\hline NCT01360593 & II & Gem + Xeloda followed by SBRT ( $12 \mathrm{~Gy} \times 3$ fractions) & University of Pittsburgh & July 2011 \\
\hline NCT00609336 & II & Gem + Xeloda + oxaliplatin + Cisplatin + IMRT & University of Washington & January 2008 \\
\hline NCT00557492 & II & Gem + Avastin + radiation (30 Gy in 10 fractions) & University of Pittsburgh & December 2006 \\
\hline NCT00763516 & II & $\mathrm{Xeloda}+$ proton radiation $(50.4 \mathrm{CGE})$ & University of Florida & September 2008 \\
\hline NCT01494155 & II & Xeloda + hydroxychloroquine + proton radiation (five fractions) & Massachusetts General Hospital & December 2011 \\
\hline NCT01065870 & II & $\mathrm{Gem}+\mathrm{Xeloda}+$ docetaxel $+/-$ radiation $(50.4 \mathrm{~Gy})$ & Columbia University & December 2009 \\
\hline
\end{tabular}

$C R T$ chemoradiation therapy, $R T$ radiation therapy, Gem gemcitabine, FOLFIRINOX combination chemotherapy of 5-FU leucovorin, oxaliplatin, and irinotecan, Gy gray

and involvement of the portal vein or superior mesenteric vein has been investigated [73-76]. The work by Chatterjee and colleagues indicates that tumor invasion into lymphatic spaces was associated with a higher percentage of lymph node positivity but not in other clinical outcomes; tumor invasion into vasculature was associated with a worse DFS and OS than in patients with no lymphovascular invasion or lymphatic invasion alone [74]. In an extension of the same dataset, Chatterjee and colleagues presented data suggesting that the presence of intraneural and PNI in the surgical specimen correlated with a worse DFS and OS [73]. A similar outcome was described by Takahashi and colleagues who noted that nodal involvement and PNI in the surgical specimen portend a worse disease-free survival, but went on to note that PNI was associated with a statistically higher risk of recurrence within the abdominal cavity while nodal involvement was the single factor associated with an increased risk of distant recurrence [75]. Lastly, Wang and colleagues noted that histopathologic tumor involvement of the resected portal vein and superior mesenteric vein was associated with greater intraoperative blood loss, larger tumor size, increased margin-positive resection, and a greater risk of local recurrence and distant metastasis [76]. In summary, PNI and vascular involvement may be associated with a worse outcome for pancreatic cancer patients and may warrant more aggressive therapy.

\section{Current research protocols}

Active areas of research on the use of neoadjuvant radiation in borderline resectable pancreatic cancer will likely focus on the use of FOLFIRINOX and stereotactic body radiation therapy (SBRT). Given the interest in FOLFIRINOX and the survival advantage seen in metastatic patients, it follows that many clinical trials will be applying this chemotherapy regimen in the neoadjuvant and adjuvant setting [77]. Stereotactic radiation therapy has gained active interest in the pancreatic cancer community, though its utility has primarily been limited to unresectable disease [78-83]. It follows that ongoing and upcoming protocols will implement SBRT in the treatment 
of borderline tumors to further improve resectability and R0 resection rates. Additional concepts may focus on a radiation boost to the regions of vessel involvement to better facilitate margin-negative surgery. Tables 6 and 7 list the actively accruing clinical trials investigating neoadjuvant therapy in resectable and borderline resectable pancreatic cancer as identified in clinicaltrials.gov.

\section{Summary}

Resectable and borderline resectable pancreatic cancer patients are a group of patients in whom neoadjuvant radiation therapy may provide a significant benefit. It is important for the radiation oncologist to understand this data to best implement it not only into his or her own practice but also to make appropriate recommendations in the multi-disciplinary setting. As detailed in our review, the use of radiation therapy in this population may allow not only for resectability in the borderline setting but also an R0 resection, thus improving a patient's chance for cure. R0 resection rates may be improved with the addition of chemoradiation neoadjuvantly compared to chemotherapy alone in the setting of borderline resectable pancreatic cancers. Ongoing clinical trials will help define the role of specific chemotherapies and stereotactic body radiation therapy in the management of borderline resectable pancreatic cancer.

At this time, the standard of care for the utilization of neoadjuvant chemoradiation in the setting of a resectable or borderline resectable tumor involves between 1 and 3 cycles of chemotherapy prior to chemoradiation. For patients with a poor performance status or concern for early progression, gemcitabine alone is the most common first agent applied. However, if the patient has a better performance status, combination chemotherapy, usually GTX (gemcitabine-taxotereXeloda (capecitabine)) or FOLFIRINOX, may be considered prior to chemoradiation prior to chemoradiation. While combination chemotherapy may offer a stronger treatment regimen, it comes at a risk of significant grade $3 / 4$ toxicities and should be used with caution [77].

If the patient does not develop metastatic disease during the application of initial chemotherapy, radiation therapy is subsequently administered with chemotherapy. A dose of 50 to 54 Gy may be delivered to the primary tumor and peripancreatic lymph nodes using conventional or threedimensional conformal radiation beams. If using doses greater than 54 Gy, IMRT with image guidance is necessary. Ideally, this is to be done in a clinical trial. The Radiation Therapy Oncology Group is conducting a dose escalation study in which the primary tumor will receive $63 \mathrm{~Gy}$ for unresectable tumors. Active participation in this upcoming protocol is encouraged.
Finally, altered fractionation, including SBRT, may be used in the neoadjuvant setting. Inclusion in a clinical trial is the recommended scenario for using this method. Early data has delivered very high doses in a single fraction, though fractionation (typically five fractions) is gaining significant popularity [78-83]. Despite encouraging early data, long-term prospective validation is necessary before this may be considered the standard of care. With that said, the potential benefits to SBRT in terms of reduced toxicity, increased patient convenience, and reduced time to resection cannot be overlooked.

Conflict of interest Rachit Kumar declares that he has no conflicts of interest. Salma Jabbour declares that she has no conflicts of interest.

\section{References}

1. Katz MH, Hwang R, Fleming JB, Evans DB (2008) Tumor-nodemetastasis staging of pancreatic adenocarcinoma. CA Cancer J Clin 58(2):111-125. doi:10.3322/CA.2007.0012

2. Vincent A, Herman J, Schulick R, Hruban RH, Goggins M (2011) Pancreatic cancer. Lancet 378(9791):607-620. doi:10.1016/S01406736(10)62307-0

3. Callery MP, Chang KJ, Fishman EK, Talamonti MS, William Traverso L, Linehan DC (2009) Pretreatment assessment of resectable and borderline resectable pancreatic cancer: Expert consensus statement. Ann Surg Oncol 16(7):1727-1733. doi:10.1245/s10434009-0408-6

4. Edge SB, Compton CC (2010) The american joint committee on cancer: The 7th edition of the AJCC cancer staging manual and the future of TNM. Ann Surg Oncol 17(6):1471-1474. doi:10.1245/ s10434-010-0985-4

5. Katz MH, Pisters PW, Evans DB, Sun CC, Lee JE, Fleming JB, Vauthey JN, Abdalla EK, Crane CH, Wolff RA, Varadhachary GR, Hwang RF (2008) Borderline resectable pancreatic cancer: The importance of this emerging stage of disease. J Am Coll Surg 206(5): 833-846. doi:10.1016/j.jamcollsurg.2007.12.020, discussion 846-838

6. Evans DB, Varadhachary GR, Crane CH, Sun CC, Lee JE, Pisters PW, Vauthey JN, Wang H, Cleary KR, Staerkel GA, Charnsangavej C, Lano EA, Ho L, Lenzi R, Abbruzzese JL, Wolff RA (2008) Preoperative gemcitabine-based chemoradiation for patients with resectable adenocarcinoma of the pancreatic head. J Clin Oncol 26(21):3496-3502. doi:10.1200/JCO.2007.15.8634

7. Berger AC, Winter K, Hoffman JP, Regine WF, Abrams RA, Safran H, Freedman GM, Benson AB 3rd, Macdonald J, Willett CG (2012) Five year results of US Intergroup/RTOG 9704 with postoperative CA $19-9</=90 \mathrm{U} / \mathrm{mL}$ and comparison to the CONKO-001 Trial. Int J Radiat Oncol Biol Phys 84(3):e291-297. doi:10.1016/j.ijrobp. 2012.04.035

8. Tempero MA, Arnoletti JP, Behrman SW, Ben-Josef E, Benson AB 3rd, Casper ES, Cohen SJ, Czito B, Ellenhorn JD, Hawkins WG, Herman J, Hoffman JP, Ko A, Komanduri S, Koong A, Ma WW, Malafa MP, Merchant NB, Mulvihill SJ, Muscarella P 2nd, Nakakura EK, Obando J, Pitman MB, Sasson AR, Tally A, Thayer SP, Whiting S, Wolff RA, Wolpin BM, Freedman-Cass DA, Shead DA (2012) Pancreatic adenocarcinoma, version 2.2012: featured updates to the NCCN Guidelines. J Natl Compr Canc Netw 10(6):703-713

9. Ishikawa $\mathrm{O}$, Ohhigashi $H$, Sasaki Y, Imaoka S, Iwanaga T, Teshima T, Chatani M, Inoue T, Fujita M, Tanaka S et al (1988) The histopathological effect of preoperative irradiation in adenocarcinoma of 
the periampullary region. Nihon Gan Chiryo Gakkai Shi 23(3):720 727

10. Evans DB, Rich TA, Byrd DR, Cleary KR, Connelly JH, Levin B, Charnsangavej C, Fenoglio CJ, Ames FC (1992) Preoperative chemoradiation and pancreaticoduodenectomy for adenocarcinoma of the pancreas. Arch Surg 127(11):1335-1339

11. Washington MK, Berlin J, Branton PA, Burgart LJ, Carter DK, Compton CC, Frankel WL, Jessup JM, Kakar S, Minsky B, Nakhleh RE, Vauthey JN (2010) Protocol for the examination of specimens from patients with carcinoma of the intrahepatic bile ducts. Arch Pathol Lab Med 134(4):e14-18. doi:10.1043/1543-2165-134.4.e14

12. Zhao Q, Rashid A, Gong Y, Katz MH, Lee JE, Wolf R, Balachandran A, Varadhachary GR, Pisters PW, Wang H, Gomez HF, Abbruzzese JL, Fleming JB (2012) Pathologic complete response to neoadjuvant therapy in patients with pancreatic ductal adenocarcinoma is associated with a better prognosis. Ann Diagn Pathol 16(1):29-37. doi:10. 1016/j.anndiagpath.2011.08.005

13. White RR, Xie HB, Gottfried MR, Czito BG, Hurwitz HI, Morse MA, Blobe GC, Paulson EK, Baillie J, Branch MS, Jowell PS, Clary BM, Pappas TN, Tyler DS (2005) Significance of histological response to preoperative chemoradiotherapy for pancreatic cancer. Ann Surg Oncol 12(3):214-221. doi:10.1245/ASO.2005.03.105

14. Chatterjee D, Katz MH, Rashid A, Varadhachary GR, Wolff RA, Wang H, Lee JE, Pisters PW, Vauthey JN, Crane C, Gomez HF, Abbruzzese JL, Fleming JB (2012) Histologic grading of the extent of residual carcinoma following neoadjuvant chemoradiation in pancreatic ductal adenocarcinoma: A predictor for patient outcome. Cancer 118(12):3182-3190. doi:10.1002/cncr.26651

15. Moutardier V, Magnin V, Turrini O, Viret F, Hennekinne-Mucci S, Goncalves A, Pesenti C, Guiramand J, Lelong B, Giovannini M, Monges G, Houvenaeghel G, Delpero JR (2004) Assessment of pathologic response after preoperative chemoradiotherapy and surgery in pancreatic adenocarcinoma. Int J Radiat Oncol Biol Phys 60(2):437-443. doi:10.1016/j.ijrobp.2004.04.004

16. Murata Y, Mizuno S, Kishiwada M, Hamada T, Usui M, Sakurai H, Tabata M, Inoue H, Shiraishi T, Isaji S (2012) Impact of histological response after neoadjuvant chemoradiotherapy on recurrence-free survival in UICC-T3 pancreatic adenocarcinoma but not in UICCT4. Pancreas 41(1):130-136. doi:10.1097/MPA.0b013e3182236442

17. Le Scodan R, Mornex F, Partensky C, Mercier C, Valette PJ, Ychou M, Roy P, Scoazec JY (2008) Histopathological response to preoperative chemoradiation for resectable pancreatic adenocarcinoma: The French phase II FFCD 9704-SFRO Trial. Am J Clin Oncol 31(6):545-552. doi:10.1097/COC.0b013e318172d5c5

18. Palmer DH, Stocken DD, Hewitt H, Markham CE, Hassan AB, Johnson PJ, Buckels JA, Bramhall SR (2007) A randomized phase 2 trial of neoadjuvant chemotherapy in resectable pancreatic cancer: Gemcitabine alone versus gemcitabine combined with cisplatin. Ann Surg Oncol 14(7):2088-2096. doi:10.1245/s10434-007-9384-x

19. Heinrich S, Pestalozzi BC, Schafer M, Weber A, Bauerfeind P, Knuth A, Clavien PA (2008) Prospective phase II trial of neoadjuvant chemotherapy with gemcitabine and cisplatin for resectable adenocarcinoma of the pancreatic head. J Clin Oncol 26(15):2526-2531. doi:10.1200/JCO.2007.15.5556

20. Sahora K, Kuehrer I, Schindl M, Koelblinger C, Goetzinger P, Gnant M (2011) NeoGemTax: Gemcitabine and docetaxel as neoadjuvant treatment for locally advanced nonmetastasized pancreatic cancer. World J Surg 35(7):1580-1589. doi:10.1007/s00268-011-1113-8

21. Sahora K, Kuehrer I, Eisenhut A, Akan B, Koellblinger C, Goetzinger P, Teleky B, Jakesz R, Peck-Radosavljevic M, Ba'ssalamah A, Zielinski C, Gnant M (2011) NeoGemOx: Gemcitabine and oxaliplatin as neoadjuvant treatment for locally advanced, nonmetastasized pancreatic cancer. Surgery 149(3):311-320. doi:10. 1016/j.surg.2010.07.048

22. Shinoto M, Yamada S, Yasuda S, Imada H, Shioyama Y, Honda H, Kamada T, Tsujii H, Saisho H (2012) Phase 1 trial of preoperative, short-course carbon-ion radiotherapy for patients with resectable pancreatic cancer. Cancer. doi:10.1002/cncr.27723

23. Pipas JM, Barth RJ Jr, Zaki B, Tsapakos MJ, Suriawinata AA, Bettmann MA, Cates JM, Ripple GH, Sutton JE, Gordon SR, McDonnell CE, Perez RP, Redfield N, Meyer LP, Marshall JF, Cole BF, Colacchio TA (2005) Docetaxel/gemcitabine followed by gemcitabine and external beam radiotherapy in patients with pancreatic adenocarcinoma. Ann Surg Oncol 12(12):995-1004. doi:10. 1245/ASO.2005.04.503

24. Varadhachary GR, Wolff RA, Crane CH, Sun CC, Lee JE, Pisters PW, Vauthey JN, Abdalla E, Wang H, Staerkel GA, Lee JH, Ross WA, Tamm EP, Bhosale PR, Krishnan S, Das P, Ho L, Xiong H, Abbruzzese JL, Evans DB (2008) Preoperative gemcitabine and cisplatin followed by gemcitabine-based chemoradiation for resectable adenocarcinoma of the pancreatic head. J Clin Oncol 26(21): 3487-3495. doi:10.1200/JCO.2007.15.8642

25. Landry J, Catalano PJ, Staley C, Harris W, Hoffman J, Talamonti M, Xu N, Cooper H, Benson AB 3rd (2010) Randomized phase II study of gemcitabine plus radiotherapy versus gemcitabine, 5-fluorouracil, and cisplatin followed by radiotherapy and 5-fluorouracil for patients with locally advanced, potentially resectable pancreatic adenocarcinoma. J Surg Oncol 101(7):587-592. doi:10.1002/jso.21527

26. Pipas JM, Zaki BI, McGowan MM, Tsapakos MJ, Ripple GH, Suriawinata AA, Tsongalis GJ, Colacchio TA, Gordon SR, Sutton JE, Srivastava A, Smith KD, Gardner TB, Korc M, Davis TH, Preis M, Tarczewski SM, Mackenzie TA, Barth RJ Jr (2012) Neoadjuvant cetuximab, twice-weekly gemcitabine, and intensity-modulated radiotherapy (IMRT) in patients with pancreatic adenocarcinoma. Ann Oncol. doi:10.1093/annonc/mds109

27. Yeung RS, Weese JL, Hoffman JP, Solin LJ, Paul AR, Engstrom PF, Litwin S, Kowalyshyn MJ, Eisenberg BL (1993) Neoadjuvant chemoradiation in pancreatic and duodenal carcinoma. A phase II study. Cancer 72(7):2124-2133

28. Pisters PW, Wolff RA, Janjan NA, Cleary KR, Charnsangavej C, Crane CN, Lenzi R, Vauthey JN, Lee JE, Abbruzzese JL, Evans DB (2002) Preoperative paclitaxel and concurrent rapid-fractionation radiation for resectable pancreatic adenocarcinoma: toxicities, histologic response rates, and event-free outcome. J Clin Oncol 20(10):2537-2544

29. Ammori JB, Colletti LM, Zalupski MM, Eckhauser FE, Greenson JK, Dimick J, Lawrence TS, McGinn CJ (2003) Surgical resection following radiation therapy with concurrent gemcitabine in patients with previously unresectable adenocarcinoma of the pancreas. J Gastrointest Surg 7(6):766-772

30. Magnin V, Moutardier V, Giovannini MH, Lelong B, Giovannini M, Viret F, Monges G, Bardou VJ, Alzieu C, Delpero JR (2003) Neoadjuvant preoperative chemoradiation in patients with pancreatic cancer. Int J Radiat Oncol Biol Phys 55(5):1300-1304

31. Joensuu TK, Kiviluoto T, Karkkainen P, Vento P, Kivisaari L, Tenhunen M, Westberg R, Elomaa I (2004) Phase I-II trial of twice-weekly gemcitabine and concomitant irradiation in patients undergoing pancreaticoduodenectomy with extended lymphadenectomy for locally advanced pancreatic cancer. Int J Radiat Oncol Biol Phys 60(2):444-452. doi:10.1016/j.ijrobp.2004.03.026

32. Talamonti MS, Small W Jr, Mulcahy MF, Wayne JD, Attaluri V, Colletti LM, Zalupski MM, Hoffman JP, Freedman GM, Kinsella TJ, Philip PA, McGinn CJ (2006) A multi-institutional phase II trial of preoperative full-dose gemcitabine and concurrent radiation for patients with potentially resectable pancreatic carcinoma. Ann Surg Oncol 13(2):150-158. doi:10.1245/ASO.2006.03.039

33. Lind PA, Isaksson B, Almstrom M, Johnsson A, Albiin N, Bystrom P, Permert J (2008) Efficacy of preoperative radiochemotherapy in patients with locally advanced pancreatic carcinoma. Acta Oncol 47(3):413-420. doi:10.1080/02841860701592384

34. Marti JL, Hochster HS, Hiotis SP, Donahue B, Ryan T, Newman E (2008) Phase I/II trial of induction chemotherapy followed by concurrent chemoradiotherapy and surgery for locoregionally advanced 
pancreatic cancer. Ann Surg Oncol 15(12):3521-3531. doi:10.1245/ s10434-008-0152-3

35. Turrini O, Ychou M, Moureau-Zabotto L, Rouanet P, Giovannini M, Moutardier V, Azria D, Delpero JR, Viret F (2010) Neoadjuvant docetaxel-based chemoradiation for resectable adenocarcinoma of the pancreas: new neoadjuvant regimen was safe and provided an interesting pathologic response. Eur J Surg Oncol 36(10):987-992. doi:10.1016/j.ejso.2010.07.003

36. Leone F, Gatti M, Massucco P, Colombi F, Sperti E, Campanella D, Regge D, Gabriele P, Capussotti L, Aglietta M (2012) Induction gemcitabine and oxaliplatin therapy followed by a twice-weekly infusion of gemcitabine and concurrent external-beam radiation for neoadjuvant treatment of locally advanced pancreatic cancer: A single institutional experience. Cancer. doi:10.1002/cncr.27736

37. Staley CA, Lee JE, Cleary KR, Abbruzzese JL, Fenoglio CJ, Rich TA, Evans DB (1996) Preoperative chemoradiation, pancreaticoduodenectomy, and intraoperative radiation therapy for adenocarcinoma of the pancreatic head. Am J Surg 171(1):118-124. doi:10. 1016/S0002-9610(99)80085-3, discussion 124-115

38. Mehta VK, Poen JC, Ford JM, Oberhelman HA, Vierra MA, Bastidas AJ, Fisher GA (2001) Protracted venous infusion 5-fluorouracil with concomitant radiotherapy compared with bolus 5-fluorouracil for unresectable pancreatic cancer. Am J Clin Oncol 24(2):155-159

39. Spitz FR, Abbruzzese JL, Lee JE, Pisters PW, Lowy AM, Fenoglio CJ, Cleary KR, Janjan NA, Goswitz MS, Rich TA, Evans DB (1997) Preoperative and postoperative chemoradiation strategies in patients treated with pancreaticoduodenectomy for adenocarcinoma of the pancreas. J Clin Oncol 15(3):928-937

40. Piperdi M, McDade TP, Shim JK, Piperdi B, Kadish SP, Sullivan ME, Whalen GF, Tseng JF (2010) A neoadjuvant strategy for pancreatic adenocarcinoma increases the likelihood of receiving all components of care: Lessons from a single-institution database. HPB (Oxford) 12(3):204-210. doi:10.1111/j.1477-2574.2009.00150.x

41. Stokes JB, Nolan NJ, Stelow EB, Walters DM, Weiss GR, de Lange EE, Rich TA, Adams RB, Bauer TW (2011) Preoperative capecitabine and concurrent radiation for borderline resectable pancreatic cancer. Ann Surg Oncol 18(3):619-627. doi:10.1245/s10434-010-1456-7

42. Breslin TM, Hess KR, Harbison DB, Jean ME, Cleary KR, Dackiw AP, Wolff RA, Abbruzzese JL, Janjan NA, Crane CH, Vauthey JN, Lee JE, Pisters PW, Evans DB (2001) Neoadjuvant chemoradiotherapy for adenocarcinoma of the pancreas: Treatment variables and survival duration. Ann Surg Oncol 8(2):123-132

43. Calvo FA, Matute R, Garcia-Sabrido JL, Gomez-Espi M, Martinez NE, Lozano MA, Herranz R (2004) Neoadjuvant chemoradiation with tegafur in cancer of the pancreas: Initial analysis of clinical tolerance and outcome. Am J Clin Oncol 27(4):343-349

44. Brown KM, Siripurapu V, Davidson M, Cohen SJ, Konski A, Watson JC, Li T, Ciocca V, Cooper H, Hoffman JP (2008) Chemoradiation followed by chemotherapy before resection for borderline pancreatic adenocarcinoma. Am J Surg 195(3):318-321. doi:10.1016/j.amjsurg. 2007.12.017

45. Satoi S, Yanagimoto H, Toyokawa H, Takahashi K, Matsui Y, Kitade H, Mergental H, Tanigawa N, Takai S, Kwon AH (2009) Surgical results after preoperative chemoradiation therapy for patients with pancreatic cancer. Pancreas 38(3):282-288. doi:10.1097/MPA. 0b013e31819438c3

46. Chun YS, Milestone BN, Watson JC, Cohen SJ, Burtness B, Engstrom PF, Haluszka O, Tokar JL, Hall MJ, Denlinger CS, Astsaturov I, Hoffman JP (2010) Defining venous involvement in borderline resectable pancreatic cancer. Ann Surg Oncol 17(11): 2832-2838. doi:10.1245/s10434-010-1284-9

47. McClaine RJ, Lowy AM, Sussman JJ, Schmulewitz N, Grisell DL, Ahmad SA (2010) Neoadjuvant therapy may lead to successful surgical resection and improved survival in patients with borderline resectable pancreatic cancer. HPB (Oxford) 12(1):73-79. doi:10. 1111/j.1477-2574.2009.00136.x
48. Kang CM, Chung YE, Park JY, Sung JS, Hwang HK, Choi HJ, Kim H, Song SY, Lee WJ (2012) Potential contribution of preoperative neoadjuvant concurrent chemoradiation therapy on margin-negative resection in borderline resectable pancreatic cancer. J Gastrointest Surg 16(3):509-517. doi:10.1007/s11605-011-1784-3

49. Patel M, Hoffe S, Malafa M, Hodul P, Klapman J, Centeno B, Kim J, Helm J, Valone T, Springett G (2011) Neoadjuvant GTX chemotherapy and IMRT-based chemoradiation for borderline resectable pancreatic cancer. J Surg Oncol 104(2):155-161. doi:10.1002/jso.21954

50. Takahashi S, Kinoshita T, Konishi M, Gotohda N, Kato Y, Kobayashi T, Mitsunaga S, Nakachi K, Ikeda M (2011) Borderline resectable pancreatic cancer: rationale for multidisciplinary treatment. J Hepatobiliary Pancreat Sci 18(4):567-574. doi:10.1007/s00534011-0371-z

51. Arvold ND, Ryan DP, Niemierko A, Blaszkowsky LS, Kwak EL, Wo JY, Allen JN, Clark JW, Wadlow RC, Zhu AX, Fernandez-Del Castillo C, Hong TS (2012) Long-term outcomes of neoadjuvant chemotherapy before chemoradiation for locally advanced pancreatic cancer. Cancer 118(12):3026-3035. doi:10.1002/cncr.26633

52. Barugola G, Partelli S, Crippa S, Capelli P, D'Onofrio M, Pederzoli P, Falconi M (2012) Outcomes after resection of locally advanced or borderline resectable pancreatic cancer after neoadjuvant therapy. Am J Surg 203(2):132-139. doi:10.1016/j.amjsurg.2011.03.008

53. Estrella JS, Rashid A, Fleming JB, Katz MH, Lee JE, Wolf RA, Varadhachary GR, Pisters PW, Abdalla EK, Vauthey JN, Wang H, Gomez HF, Evans DB, Abbruzzese JL (2012) Post-therapy pathologic stage and survival in patients with pancreatic ductal adenocarcinoma treated with neoadjuvant chemoradiation. Cancer 118(1): 268-277. doi:10.1002/cncr.26243

54. Hosein PJ, Macintyre J, Kawamura C, Maldonado JC, Ernani V, Loaiza-Bonilla A, Narayanan G, Ribeiro A, Portelance L, Merchan JR, Levi JU, Rocha-Lima CM (2012) A retrospective study of neoadjuvant FOLFIRINOX in unresectable or borderline-resectable locally advanced pancreatic adenocarcinoma. BMC Cancer 12:199. doi:10.1186/1471-2407-12-199

55. Sho M, Akahori T, Tanaka T, Kinoshita S, Tamamoto T, Nomi T, Yamato I, Hokuto D, Yasuda S, Kawaguchi C, Nishiofuku H, Marugami N, Enomonoto Y, Kasai T, Hasegawa M, Kichikawa K, Nakajima Y (2012) Pathological and clinical impact of neoadjuvant chemoradiotherapy using full-dose gemcitabine and concurrent radiation for resectable pancreatic cancer. J Hepatobiliary Pancreat Sci. doi:10.1007/s00534-012-0532-8

56. Stessin AM, Meyer JE, Sherr DL (2008) Neoadjuvant radiation is associated with improved survival in patients with resectable pancreatic cancer: an analysis of data from the Surveillance, Epidemiology, and End Results (SEER) registry. Int J Radiat Oncol Biol Phys 72(4): 1128-1133. doi:10.1016/j.ijrobp.2008.02.065

57. Artinyan A, Anaya DA, McKenzie S, Ellenhorn JD, Kim J (2011) Neoadjuvant therapy is associated with improved survival in resectable pancreatic adenocarcinoma. Cancer 117(10):2044-2049. doi:10. $1002 /$ cncr.25763

58. Sata N, Kurashina K, Nagai H, Nagakawa T, Ishikawa O, Ohta T, Oka M, Kinoshita H, Kimura W, Shimada H, Tanaka M, Nakao A, Hirata K, Yasuda H (2009) The effect of adjuvant and neoadjuvant chemo(radio)therapy on survival in 1,679 resected pancreatic carcinoma cases in Japan: report of the national survey in the 34th annual meeting of Japanese Society of Pancreatic Surgery. J Hepatobiliary Pancreat Surg 16(4):485-492. doi:10.1007/s00534-009-0077-7

59. Laurence JM, Tran PD, Morarji K, Eslick GD, Lam VW, Sandroussi C (2011) A systematic review and meta-analysis of survival and surgical outcomes following neoadjuvant chemoradiotherapy for pancreatic cancer. J Gastrointest Surg 15(11):2059-2069. doi:10. 1007/s11605-011-1659-7

60. Assifi MM, Lu X, Eibl G, Reber HA, Li G, Hines OJ (2011) Neoadjuvant therapy in pancreatic adenocarcinoma: a meta-analysis of phase II trials. Surgery 150(3):466-473. doi:10.1016/j.surg.2011.07.006 
61. Gillen S, Schuster T, Meyer Zum Buschenfelde C, Friess H, Kleeff J (2010) Preoperative/neoadjuvant therapy in pancreatic cancer: a systematic review and meta-analysis of response and resection percentages. PLoS Med 7(4):e1000267. doi:10.1371/journal.pmed. 1000267

62. Andriulli A, Festa V, Botteri E, Valvano MR, Koch M, Bassi C, Maisonneuve P, Sebastiano PD (2012) Neoadjuvant/preoperative gemcitabine for patients with localized pancreatic cancer: a metaanalysis of prospective studies. Ann Surg Oncol 19(5):1644-1662. doi:10.1245/s10434-011-2110-8

63. Chuong MD, Hayman TJ, Patel MR, Russell MS, Malafa MP, Hodul PJ, Springett GM, Choi J, Shridhar R, Hoffe SE (2011) Comparison of 1-, 2-, and 3-dimensional tumor response assessment after neoadjuvant GTX-RT in borderline-resectable pancreatic cancer. Gastrointest Cancer Res 4(4):128-134

64. Katz MH, Fleming JB, Bhosale P, Varadhachary G, Lee JE, Wolff R, Wang H, Abbruzzese J, Pisters PW, Vauthey JN, Charnsangavej C, Tamm E, Crane CH, Balachandran A (2012) Response of borderline resectable pancreatic cancer to neoadjuvant therapy is not reflected by radiographic indicators. Cancer. doi:10.1002/cncr.27636

65. Choi M, Heilbrun LK, Venkatramanamoorthy R, Lawhorn-Crews JM, Zalupski MM, Shields AF (2010) Using 18F-fluorodeoxyglucose positron emission tomography to monitor clinical outcomes in patients treated with neoadjuvant chemo-radiotherapy for locally advanced pancreatic cancer. Am J Clin Oncol 33(3):257-261. doi:10.1097/ COC.0b013e3181a76a0b

66. Maisey NR, Webb A, Flux GD, Padhani A, Cunningham DC, Ott RJ, Norman A (2000) FDG-PET in the prediction of survival of patients with cancer of the pancreas: a pilot study. Br J Cancer 83(3):287-293. doi:10.1054/bjoc.2000.1166

67. Yoshioka M, Sato T, Furuya T, Shibata S, Andoh H, Asanuma Y, Hatazawa J, Shimosegawa E, Koyama K, Yamamoto Y (2004) Role of positron emission tomography with 2-deoxy-2-[18F]fluoro-D-glucose in evaluating the effects of arterial infusion chemotherapy and radiotherapy on pancreatic cancer. J Gastroenterol 39(1):50-55. doi: 10.1007/s00535-003-1244-2

68. Rose DM, Delbeke D, Beauchamp RD, Chapman WC, Sandler MP, Sharp KW, Richards WO, Wright JK, Frexes ME, Pinson CW, Leach SD (1999) 18Fluorodeoxyglucose-positron emission tomography in the management of patients with suspected pancreatic cancer. Ann Surg 229(5):729-737, discussion 737-728

69. Bang S, Chung HW, Park SW, Chung JB, Yun M, Lee JD, Song SY (2006) The clinical usefulness of 18-fluorodeoxyglucose positron emission tomography in the differential diagnosis, staging, and response evaluation after concurrent chemoradiotherapy for pancreatic cancer. J Clin Gastroenterol 40(10):923-929. doi:10.1097/01.mcg. 0000225672.68852 .05

70. Preis M, Gardner TB, Gordon SR, Pipas JM, Mackenzie TA, Klein EE, Longnecker DS, Gutmann EJ, Sempere LF, Korc M (2011) MicroRNA-10b expression correlates with response to neoadjuvant therapy and survival in pancreatic ductal adenocarcinoma. Clin Cancer Res 17(17):5812-5821. doi:10.1158/1078-0432.CCR-11-0695

71. Iacobuzio-Donahue CA, Fu B, Yachida S, Luo M, Abe H, Henderson CM, Vilardell F, Wang Z, Keller JW, Banerjee P, Herman JM, Cameron JL, Yeo CJ, Halushka MK, Eshleman JR, Raben M, Klein AP, Hruban RH, Hidalgo M, Laheru D (2009) DPC4 gene status of the primary carcinoma correlates with patterns of failure in patients with pancreatic cancer. J Clin Oncol 27(11):1806-1813. doi: 10.1200/JCO.2008.17.7188

72. Katz MH, Varadhachary GR, Fleming JB, Wolff RA, Lee JE, Pisters PW, Vauthey JN, Abdalla EK, Sun CC, Wang H, Crane CH, Lee JH, Tamm EP, Abbruzzese JL, Evans DB (2010) Serum CA 19-9 as a marker of resectability and survival in patients with potentially resectable pancreatic cancer treated with neoadjuvant chemoradiation. Ann Surg Oncol 17(7):1794-1801. doi:10.1245/s10434-010-0943-1
73. Chatterjee D, Katz MH, Rashid A, Wang H, Iuga AC, Varadhachary GR, Wolff RA, Lee JE, Pisters PW, Crane CH, Gomez HF, Abbruzzese JL, Fleming JB (2012) Perineural and intraneural invasion in posttherapy pancreaticoduodenectomy specimens predicts poor prognosis in patients with pancreatic ductal adenocarcinoma. Am J Surg Pathol 36(3):409-417. doi:10.1097/PAS. 0b013e31824104c5

74. Chatterjee D, Rashid A, Wang H, Katz MH, Wolff RA, Varadhachary GR, Lee JE, Pisters PW, Gomez HF, Abbruzzese JL, Fleming JB (2012) Tumor invasion of muscular vessels predicts poor prognosis in patients with pancreatic ductal adenocarcinoma who have received neoadjuvant therapy and pancreaticoduodenectomy. Am J Surg Pathol 36(4):552-559. doi:10.1097/PAS.0b013e318240c1c0

75. Takahashi H, Ohigashi H, Ishikawa O, Gotoh K, Yamada T, Nagata S, Tomita Y, Eguchi H, Doki Y, Yano M (2012) Perineural invasion and lymph node involvement as indicators of surgical outcome and pattern of recurrence in the setting of preoperative gemcitabine-based chemoradiation therapy for resectable pancreatic cancer. Ann Surg 255(1):95-102. doi:10.1097/SLA.0b013e31823d813c

76. Wang J, Estrella JS, Peng L, Rashid A, Varadhachary GR, Wang H, Lee JE, Pisters PW, Vauthey JN, Katz MH, Gomez HF, Evans DB, Abbruzzese JL, Fleming JB (2012) Histologic tumor involvement of superior mesenteric vein/portal vein predicts poor prognosis in patients with stage II pancreatic adenocarcinoma treated with neoadjuvant chemoradiation. Cancer 118(15):3801-3811. doi:10.1002/cncr. 26717

77. Conroy T, Desseigne F, Ychou M, Bouche O, Guimbaud R, Becouarn Y, Adenis A, Raoul JL, Gourgou-Bourgade S, de la Fouchardiere C, Bennouna J, Bachet JB, Khemissa-Akouz F, PereVerge D, Delbaldo C, Assenat E, Chauffert B, Michel P, MontotoGrillot C, Ducreux M (2011) FOLFIRINOX versus gemcitabine for metastatic pancreatic cancer. N Engl J Med 364(19):1817-1825. doi: 10.1056/NEJMoa1011923

78. Schellenberg D, Goodman KA, Lee F, Chang S, Kuo T, Ford JM, Fisher GA, Quon A, Desser TS, Norton J, Greco R, Yang GP, Koong AC (2008) Gemcitabine chemotherapy and single-fraction stereotactic body radiotherapy for locally advanced pancreatic cancer. Int $\mathrm{J}$ Radiat Oncol Biol Phys 72(3):678-686. doi:10.1016/j.ijrobp.2008. 01.051

79. Koong AC, Le QT, Ho A, Fong B, Fisher G, Cho C, Ford J, Poen J, Gibbs IC, Mehta VK, Kee S, Trueblood W, Yang G, Bastidas JA (2004) Phase I study of stereotactic radiosurgery in patients with locally advanced pancreatic cancer. Int J Radiat Oncol Biol Phys 58(4):1017-1021. doi:10.1016/j.ijrobp.2003.11.004

80. Koong AC, Christofferson E, Le QT, Goodman KA, Ho A, Kuo T, Ford JM, Fisher GA, Greco R, Norton J, Yang GP (2005) Phase II study to assess the efficacy of conventionally fractionated radiotherapy followed by a stereotactic radiosurgery boost in patients with locally advanced pancreatic cancer. Int J Radiat Oncol Biol Phys 63(2):320-323. doi:10.1016/j.ijrobp.2005.07.002

81. Chang DT, Schellenberg D, Shen J, Kim J, Goodman KA, Fisher GA, Ford JM, Desser T, Quon A, Koong AC (2009) Stereotactic radiotherapy for unresectable adenocarcinoma of the pancreas. Cancer 115(3):665-672. doi:10.1002/cncr.24059

82. Mahadevan A, Jain S, Goldstein M, Miksad R, Pleskow D, Sawhney M, Brennan D, Callery M, Vollmer C (2010) Stereotactic body radiotherapy and gemcitabine for locally advanced pancreatic cancer. Int J Radiat Oncol Biol Phys 78(3):735-742. doi:10.1016/j.ijrobp. 2009.08.046

83. Polistina F, Costantin G, Casamassima F, Francescon P, Guglielmi R, Panizzoni G, Febbraro A, Ambrosino G (2010) Unresectable locally advanced pancreatic cancer: a multimodal treatment using neoadjuvant chemoradiotherapy (gemcitabine plus stereotactic radiosurgery) and subsequent surgical exploration. Ann Surg Oncol 17(8):20922101. doi:10.1245/s10434-010-1019-y 